\title{
Interlocuçóes entre acolhimento e crise psíquica: percepção dos trabalhadores de uma Unidade de Pronto-Atendimento
}

\section{| ${ }^{1}$ Bibiana Massem Homercher, ${ }^{2}$ André Volmer |}

Resumo: A Lei da Reforma Psiquiátrica Brasileira (RPB) dispõe sobre os cuidados e sobre a atenção à pessoa em crise psíquica e, a partir desse documento, tais demandas passaram a ser ponto-chave para os serviços de saúde, inclusive para as unidades de urgência e de emergência. Com base nessa normativa, objetivou-se analisar as noçôes que os profissionais apresentam com relação ao acolhimento e à crise psíquica. Optou-se pela pesquisa qualitativa exploratória, que realizou entrevistas semiestruturadas com 11 profissionais de distintos setores de uma Unidade de Pronto Atendimento no interior do Rio Grande do Sul. Utilizou-se a análise de conteúdo, em que se constataram duas categorias emergentes: 1) Noção de crise psíquica para os profissionais da UPA e 2) Noçôes e as práticas de acolhimento à crise psíquica exercida pelos(as) trabalhadores(as) da UPA. Os resultados evidenciam que tanto a noção de crise psíquica quanto as práticas de acolhimento empregadas pelos trabalhadores, de uma forma geral, estão associadas ao modelo biomédico, com dificuldade para ampliar a compreensão e os modos de acolher sujeitos em crise. Nesse sentido, a noção dos trabalhadores da UPA em estudo, com relação ao acolhimento da pessoa em crise psíquica, está desarticulado com o que preconiza a RPB.

Palavras-chave: acolhimento; crise psíquica; Unidade de Pronto-Atendimento (UPA).
${ }^{1}$ Universidade Franciscana. Santa Maria-RS, Brasil (bibianamh@ hotmail.com).

ORCID: 0000-0002-3832-7899

${ }^{2}$ Universidade Federal de Santa Maria. Santa Maria-RS, Brasil (andreluisvolmer@gmail.com). ORCID: 0000-0003-2048-3452

Recebido em: 02/09/2019 Aprovado em: 03/07/2020 Revisado em: 09/07/2021 


\section{Introdução}

No âmbito da saúde, a crise psíquica é considerada uma urgência, assim designada nos parâmetros psiquiátricos devido ao grau de instabilidade comportamental e emocional que uma pessoa, sob tal estado, apresenta (ALMEIDA et al., 2015). A crise seria um período em que o indivíduo não suportaria dar conta das sensaçóes afetivas que, naquela situação, lhe tomam. Em virtude disso, os saberes psiquiátrico e biomédico vigentes definem crise como imprevisibilidade e exacerbaçáo das atitudes desse indivíduo, ou seja, o ápice da desorganização de todo o seu contexto existencial. Para além do olhar biomédico, a concepção de crise é polissêmica, podendo adquirir interpretaçóes distintas, dependendo do contexto social, histórico, cultural e antropológico no qual o sujeito está inserido (PAULON et al., 2012).

As crises psíquicas são demandas pelas quais o sujeito rompe com as formas usuais de simbolizar, o que altera o regime representacional habitual e promove diferença na manifestação dos afetos, das sensaçóes, das percepçóes e dos pensamentos, ou seja, modifica a relação que, anteriormente, tinha do seu sistema de referências (JARDIM, 2014). Corroborando essa ideia, Dell'Acqua e Mezzina (2005) destacam que a crise psíquica se manifesta sempre em relação a alguma questão; portanto, ela não está no sujeito, mas se manifesta através dele.

Dentro da Rede de Atenção Psicossocial (RAPS), os Centros de Atenção Psicossocial do tipo III (CAPS III) seriam os serviços que estariam mais bem qualificados para atuar com as questôes de demandas de crise psíquica. São eles assim avaliados tanto em virtude de terem um funcionamento 24 horas, incluindo feriados e finais de semana, quanto por possuírem equipe multiprofissional - a qual tem a possibilidade de melhor lidar com os usuários ${ }^{1}$, bem como de mais precisamente conseguirem lhes ofertar um acolhimento mais amplo quando em situação de crise (BRASIL, 2011). Todavia, nem todos os municípios têm um dispositivo como CAPS III, assim como o preconizado pela Lei que estabelece a RAPS, a qual seria o ambiente ideal para atender casos de crise psíquica.

A par do exposto, temos que o município em estudo não possui CAPS III, e há casos de crise psíquica, ou seja, aos que se enquadram como demandas urgentes e emergentes, tem-se, por determinação, o seu encaminhamento à Unidade de Pronto Atendimento (UPA), para que sejam acolhidos e estabilizados. Ainda que a crise psíquica esteja relacionada com a saúde mental, ou mesmo visualizada como 
psiquiátrica, a UPA desse município é a que acolhe tais situaçôes, em conjunto com outras urgências, sejam elas pediátricas, sejam gineco-obstétricas, sejam, ainda, clínicas. (BRASIL, 2011).

A UPA tem uma importante atuação tanto na diminuição da excessiva procura por atendimentos em hospitais gerais, quanto na prevenção da superlotação hospitalar. Seu lugar na rede se constitui como porta de entrada de acesso aos serviços de saúde, priorizada pela efetividade e pela resolução de casos. Se não ocorre uma solução perante algum evento, a UPA pode encaminhar para a atenção primária ou para a internação hospitalar (SILVA et al., 2012; UCHIMURA, 2015). A relação da UPA com a RAPS é que ela também é designada para atender casos de demanda de saúde mental, embora sua atuação esteja focada na estabilização e no encaminhamento desses usuários (ANDRADE; ZEFERINO; FIALHO, 2016).

As UPAs seguem diretriz de funcionamento 24 horas, o que contempla uma recepção do usuário e um acolhimento de teor classificatório de risco, para que seja possível prestar um auxílio rápido e eficaz aos casos que surgem (BRASIL, 2002). Para isso, dentro da UPA, utilizam-se os Protocolos de Classificação de Risco, pelos quais os profissionais da saúde analisam se a situação é urgente, já que o intuito é que esses sejam os casos a dar prioridade (BRASIL, 2009; OLIVEIRA, GUIMARÁES, 2013).

Os Protocolos de Classificação de Risco têm, como objetivo, a prestação imediata dos atendimentos para aqueles que mais precisam. A ideia dessa ferramenta é auxiliar na avaliação de riscos, desenvolvida para circunstâncias catastróficas e, posteriormente, adaptadas aos serviços de urgência. Tal avaliação é útil, mas não suficiente, pois apresenta fragilidade para captar questóes subjetivas, emocionais, sociais e culturais, o que pode ser fundamental para compreender a situação de perigo em que o usuário está inscrito (BRASIL, 2009).

O acolhimento é um ato de inclusão, uma atitude de "estar com" ou "estar perto de" e pode ser concebido como uma tecnologia do encontro que possibilita a construção de redes de comunicações, ou seja, uma constituição de vínculo e de afetividade que gera produçôes de saúde (BRASIL, 2010). É também uma das diretrizes de maior relevância da Política Nacional de Humanização (PNH), pois zela para que as práticas dos trabalhadores sejam oferecidas com qualidade, compromisso, dignidade e respeito a todas as pessoas que procuram os serviços de urgência. Tal política também dispôe que os profissionais devem ser resolutivos na assistência prestada e precisam saber encaminhar os casos, de acordo com a 
necessidade, oportunizando articulação com demais serviços e garantindo a continuidade assistencial (BRASIL, 2004; 2007; 2010; 2013).

Por conseguinte, apesar de a UPA sustentar o acolhimento pelos protocolos de risco, é importante analisar que esse procedimento é algo mais amplo do que classificar o usuário. Ou seja, está associado às transformaçóes dos processos de trabalho no campo da saúde, de modo a propiciar uma recepçáo às necessidades demandadas (MINÓIA; MINOZZO, 2015).

O acolhimento apresenta sua dimensão ética, estética e política para melhorar a oferta de atendimento e a compreensão singular dos usuários. O compromisso que o trabalhador de saúde tem é, justamente, desenvolver o acolhimento, mantendo uma postura ética, proporcionando acesso, resolutividade e vínculo com o indivíduo que adentra o serviço de saúde (FERREIRA, 2009; BRASIL, 2010).

Em saúde mental, o acolhimento em casos de crise psíquica está ligado à prestação de apoio aos que precisam de uma atenção psicossocial, visto que muitos usuários se encontram em um momento de fragilidade psíquica e comportamental. Por isso, nessas circunstâncias, os profissionais precisam estar trabalhando em conjunto, para que ocorra melhor amparo - que seja de qualidade e que respeite o momento de vulnerabilidade dos sujeitos perante as situaçóes previstas (MINÓIA; MINOZZO, 2015).

Assim, este estudo se justifica pela relevância em analisar como a crise psíquica tem sido acolhida dentro de uma Unidade de Pronto Atendimento (UPA), já que ela tem sido considerada uma emergência em saúde, sendo a UPA, no caso do município estudado, a referência na rede para esse tipo de situação. Também é substancial estar mais atento em relação a como a crise psíquica tem sido gerenciada e acolhida pelos profissionais da UPA no âmbito de suas práticas (JARDIM, 2008; 2014).

Os profissionais da UPA são aqueles que constituem as intervençôes em saúde em relação ao usuário, independentemente da demanda, sendo uma delas, no entanto, pessoas em crise psíquica. As intervenções, os métodos, os movimentos dos trabalhadores da UPA em relação a essa crise definem substancialmente o direcionamento daquele indivíduo no âmbito da saúde (ALMEIDA et al., 2014).

Por conseguinte, o objetivo geral desta pesquisa é analisar como a noção de acolhimento à pessoa em crise psíquica é percebida por trabalhadores de uma UPA, em um município do interior do Estado do Rio Grande do Sul. Para isso, tem-se, por objetivos específicos, identificar as noçóes de crise psíquica para esses trabalhadores; 
compreender como eles acolhem a crise psíquica em uma UPA; discutir o lugar da crise psíquica no campo da saúde mental.

\section{Metodologia}

Esta é uma pesquisa qualitativa, de cunho descritivo-exploratório, desenvolvida em uma UPA, no interior do estado do Rio Grande do Sul. De acordo com o Ministério da Saúde, essa UPA tem porte três quanto à sua estrutura física e está equipada com salas de consultórios para diagnóstico, leitos de observação e atendimento de urgência e emergência, além de serviços laboratoriais, eletrocardiograma, raio-X e estrutura para realizar pequenas cirurgias. O serviço funciona 24 horas por dia, sem fechar aos finais de semana, e é retaguarda do Serviço de Atendimento Móvel de Urgência - SAMU (BRASIL, 2017).

A Rede de Atenção à Saúde (RAS) dessa cidade no interior do estado do Rio Grande do Sul é formada por Atenção Básica com Estratégias Saúde da Família (ESF) e Unidades Básicas de Saúde (UBS); também apresenta dois hospitais vinculados ao Sistema Único de Saúde (SUS), um espaço de acolhimento para casos emergenciais, policlínicas e ambulatórios de saúde; contém Rede de Urgência e Emergência (Unidade de Pronto Atendimento - UPA e um Pronto Atendimento - PA); além disso, apresenta quatro Centros de Atenção Psicossocial, dois CAPS AD Álcool e Drogas, um CAPS Infantil e um CAPS do tipo II. Apesar de existirem todos esses serviços, a Rede de Atenção Psicossocial (RAPS) encontrase fragilizada e fragmentada, pois não consegue lidar com as demandas de crise psíquica, quando muitos casos passam a ser encaminhados para a Unidade de Pronto Atendimento (UPA).

A rede de saúde do município estudado, apesar de apresentar vários serviços de saúde, é considerada fragmentada, pois eles atuam de forma individualizada e isolada, ou seja, cada um trabalha apenas com aquilo que lhe foi designado de maneira rígida, obtendo poucas conexôes com os outros órgãos, não apenas na RAPS, mas em seu contexto geral na RAS e também da RUE. Isso significa que os serviços não interagem, em boa parte das situaçôes, para pensar sobre o sistema de saúde da regiáo, para refletir sobre suas práticas de cuidado em saúde, para pensar sobre casos específicos que demandam mais atenção e, com isso, aprimorar seus conhecimentos referentes à oferta de atendimento integral aos usuários. 
Na UPA onde este estudo foi realizado, foram entrevistados 11 profissionais de distintos setores, os quais foram subdivididos em três grandes categorias: Gestores (administrativos e responsáveis técnicos), Trabalhadores da Saúde (médicos, enfermeiros e técnicos em enfermagem) e Trabalhadores do Apoio (recepcionistas, porteiros e higienizadores), totalizando quatro pessoas do sexo feminino e sete do sexo masculino.

Foram entrevistados profissionais que tivessem, no mínimo, seis meses de experiência de trabalho na UPA. Delimitou-se esse espaço de tempo por considerar que o trabalhador tenha vivenciado, na sua prática específica, o acolhimento de pessoas em crise psíquica, seja ele um profissional de saúde que atua diretamente com o usuário, seja ele o gestor que, em sua atuação indireta com o público, também tem sua percepção acerca do acolhimento à pessoa com crise psíquica nessa UPA. Nesse sentido, foram selecionados profissionais de setores diferentes para que se obtivesse uma visão diversificada de como tem sido conduzido o acolhimento à crise psíquica nessa instituição. Na tabela 1, encontram-se as características dos participantes das entrevistas:

Tabela 1. Dados dos Profissionais Entrevistados na UPA. Santa Maria, Rio Grande do Sul, 2019

\begin{tabular}{lllll}
\hline Profissionais & Setor & Sexo & Idade & $\begin{array}{l}\text { Trabalho de Tempo na } \\
\text { UPA (mínimo 6 meses) }\end{array}$ \\
\hline Trabalhadora da Saúde 1 & Saúde & Feminino & 49 anos & 7 anos \\
\hline Trabalhador da Saúde 2 & Saúde & Masculino & 38 anos & 6 anos \\
\hline Trabalhadora da Saúde 3 & Saúde & Feminino & 33 anos & 4 anos \\
\hline Trabalhador da Saúde 4 & Saúde & Masculino & 27 anos & 1 ano e 2 meses \\
\hline Trabalhador da Saúde 5 & Saúde & Masculino & 56 anos & 5 anos \\
\hline Trabalhadora da Saúde 6 & Saúde & Feminina & 28 anos & Aproximadamente 1 ano \\
\hline Trabalhador da Gestáo 1 & Gestão & Masculino & 45 anos & 6 anos e meio \\
\hline Trabalhador da Gestão 2 & Gestão & Masculino & 33 anos & 1 ano e 9 meses \\
\hline Trabalhador de Apoio 1 & Apoio & Masculino & 25 anos & 10 meses \\
\hline Trabalhador de Apoio 2 & Apoio & Masculino & 54 anos & 7 anos \\
\hline Trabalhador de Apoio 3 & Apoio & Feminino & 47 anos & 3 anos \\
\hline
\end{tabular}


O procedimento utilizado para a coleta de dados foi a entrevista semiestruturada, com roteiro previamente estabelecido, agendada, gravada mediante autorizaçáo do Termo de Consentimento Livre e Esclarecido (TCLE) e realizada no primeiro semestre de 2019. As entrevistas ocorreram em uma sala disponibilizada pela UPA; além disso, cada uma das entrevistas durou em média 30 minutos.

Para garantir e preservar a identidade dos sujeitos das equipes entrevistadas, os depoimentos foram identificados pelas letras " $G$ ", "S" e "A", por ser a letra inicial de cada uma das categorias, subdivididas, respectivamente, em: gestor, saúde e apoio. Dessa forma, seguirá em ordem numérica, ou seja, G1 representará o primeiro trabalhador da gestão, $S 1$ o primeiro trabalhador da saúde e A1 o primeiro trabalhador do apoio (G1, G2, S1, S2... A1, A2 e assim sucessivamente).

Após a entrevista, foi realizada a transcrição das respostas e, por fim, a análise de dados, o que permitiu a classificação em categorias emergentes, ou seja, do que surgiu após a leitura como ponto de repetição e importância, conforme as falas dos participantes. A investigação das entrevistas está baseada na análise de conteúdo de Bardin (1977), que se constitui como um modo para interpretar e analisar os dados adquiridos de uma pesquisa. A partir da leitura e da releitura do material transcrito, chegou-se a duas categorias, a saber, a primeira aborda a noção de crise psíquica para os profissionais da UPA em questão, e a segunda desenvolve a noção e as práticas de acolhimento à crise psíquica exercida pelos trabalhadores da UPA.

O projeto do estudo foi submetido ao Comitê de Ética da Universidade Federal de Santa Maria (UFSM) e aprovado, conforme o parecer de número 3.326.175/2019, seguindo os aspectos éticos, conforme Resoluçáo no 510/2016 do Conselho Nacional de Saúde, bem como a Resolução n 466/2012, fundamentada na Comissão Nacional de Ética em Pesquisa (CONEP), que orienta pesquisa com seres humanos.

\section{Resultados e Discussóes}

\section{Distintos olhares: crise psíquica em pauta}

Neste primeiro tópico, pretende-se apresentar a noção de crise psíquica construída por trabalhadores de distintos setores de uma UPA. Para isso, cabe trabalhar com as compreensões propostas por esses profissionais, na articulação com conceitos e práticas, conforme o proposto pela Reforma Psiquiátrica, principalmente quando se pensa sobre crise psíquica e saúde mental. Com essa proposta, serão trabalhadas 
questôes articuladas à normalidade e à anormalidade, a sujeito perigoso e a percepçóes biomédicas sobre a noção de crise psíquica.

Para entender as atuaçóes em saúde voltadas ao fenômeno da pessoa que se encontra em crise psíquica, cabe analisar as noçôes empreendidas pelos profissionais e como eles pensam tal contexto. Seguindo essa lógica, cumpre igualmente apreender que significados sobre crise psíquica estariam sendo produzidos pelos trabalhadores da UPA que lidam frequentemente com tal cenário.

A UPA é considerada um serviço de referência para essa cidade em casos de crise psíquica, ou seja, quando um sujeito está em surto psicótico ou em questôes associadas ao abuso de substâncias psicoativas, geralmente será encaminhado a um local de atendimento, e esse lugar, independentemente de onde ele se encontra, é a UPA. Nesse sentido, cabe percorrer a noção que os trabalhadores possuem em relação a tais demandas, pois, dessa forma, podemos refletir se há articulação com a política da Reforma Psiquiátrica.

$\mathrm{Na}$ visão de um gestor, crise psíquica seria:

Qualquer sofrimento que a pessoa tenha, de ordem emocional, que afete ela, que ela tenha alguma dor, que ela tenha algum sofrimento, que ela tenha alguma angústia, e, que muitas vezes o paciente ele não sabe tratar isso, não sabe como conviver com isso e ele acaba transbordando, ele acaba muitas vezes, extrapolando aquilo que é normal para nós. (G1)

Nota-se, na fala do trabalhador, que a pessoa quando em crise psíquica extrapolaria o nível daquilo que seria "normal para nós", demonstrando que existiria uma linha a dividir algo da ordem do "normal" de algo do espaço do "patológico". Pode-se destacar que tal lógica interferiria na noção do que seria a crise psíquica no âmbito de saúde mental, evidenciando que ainda há uma ideia manicomial a perpassar as posiçôes tomadas pelos profissionais de saúde. Tal noção de crise psíquica também encontra semelhança entre os demais trabalhadores da área da saúde e do apoio.

Bom, acho que toda a pessoa que tá fora de si, não está no seu estado normal, digamos que ele pode ser um "psi". (S1)

Crise psíquica é aquele paciente que chega aí fora de si, não diz coisa com coisa é agressivo. (A2)

Além do já mencionado termo da normalidade, temos a expressão "fora de si", a expressar que a crise psíquica seria um estado em que a pessoa teria dificuldades para se reconhecer, saber do seu eu, da sua identidade, ou seja, não responderia a questôes consideradas normais para um sujeito no que se refere a um padrão aceito 
pela sociedade. Nesse sentido, começa-se a perceber certa dificuldade, por parte dos profissionais, em relação a não conseguirem ampliar a noção que possuem de crise psíquica. Isso corrobora para um exercício das atividades voltadas às formas higienistas, focada na conduta do sujeito, na sintomatologia apresentada, ou seja, na maneira como se expressa diante do trabalhador que está a lhe acolher (AMARANTE, 2018).

Outros trabalhadores também trazem à tona tal noção, referidas nas seguintes falas:

Crise psíquica é [...] quando há uma alteração, do humor, do equilíbrio da pessoa, do equilíbrio emocional, e ela começa com atitudes diversas da normalidade, da dita normalidade, que chega a pontos assim de leva perigo pra vítima, pra paciente acometido, e também, quem está próximo, um perigo de vida pra vítima ou de lesão desse acompanhante. (S5)

Seria uma crise de loucura, de desequilíbrio [...] uma pessoa que fica desequilibrada por algum motivo. (A3)

Existem semelhanças nas falas dos trabalhadores do apoio e da saúde associadas à agressividade da pessoa que está em crise, em que a máxima atribuída seria o perigo a ela mesma ou para os demais ao seu redor. Também são observados os vocábulos "equilíbrio" (S5) e "desequilíbrio" (A3), outra vez enfatizando que há um estado de normalidade (equilíbrio psíquico) e um estado de adoecimento (crise psíquica), além de o trabalhador do apoio ter trazido a crise psíquica como uma "crise de loucura". Isso pode estar ligado ao discurso que a loucura apresenta historicamente, em que os loucos seriam pessoas perigosas, e, em virtude da sua doença, não poderiam conviver em sociedade, sendo que essa circunstância ainda pode influenciar nas práticas de saúde mental (SILVEIRA; BRAGA, 2005).

O indivíduo "louco" que se encontra "fora de si" é considerado, pela medicina, como um sujeito alienado. Através dessa conceituação, a pessoa louca estaria com seu juízo, referente a si mesmo e ao mundo, completamente alterados, o que impossibilitaria sua relação com os demais. Dessa maneira, o sujeito louco é visualizado como um risco para a sociedade. Com isso, é a partir dessa ideia que emerge a periculosidade da loucura no campo social (AMORIN; DIMENSTEIN, 2009; SOUZA et al., 2019).

É interessante analisar que loucura está associada à doença mental, como uma situação de "desequilíbrio", "fora de si", de "perigo", nas falas dos participantes. Isso demonstra que a noção de crise psíquica colocada em pauta é atravessada por uma visão biomédica, sendo fundamentada naquilo que a sociedade estipula como "normal" e como "anormal" (FRAYSE-PEREIRA, 2008; FOUCAULT, 2006; 2007; 2010; FONSECA; JAEGER, 2015). 
O conceito de normalidade e de anormalidade é vigente nas falas dos profissionais. Esses termos relacionados à loucura, e, consequentemente, ao indivíduo que demonstra um transtorno mental e/ou uma crise psíquica, é historicamente produzido. Tais vocábulos advêm do campo médico, definindo o que é patológico e o que é saudável. Isso também reverbera no cenário psicológico e social. Dessa maneira, as concepçóes de anormalidade acabam por permear a doença mental (CANGUILHEM, 1978; COELHO, 2009). Essas perspectivas influenciam na noção que a maioria dos trabalhadores tem a respeito da crise psíquica.

Novamente, pode-se observar a dificuldade que há para se estabelecer a inserção de termos e de se ligar a noção da crise psíquica a fatores mais amplos, ou seja, de se efetivar uma referência que não foque apenas no sintoma, mas que possa olhar para o sujeito de maneira integral, conforme preconiza a Reforma Psiquiátrica (DIMENSTEIN et al., 2012; JARDIM, 2014). O comentário do trabalhador da saúde segue associado a essa lógica do saber biomédico no âmbito da crise psíquica:

Crise psíquica [...] é quando há uma desorganização e/ou há uma intensificação de parâmetros (...) neurológicos e mais que bioquímico, [...] como se diz psíquico, quando existe esta desorganização e intensificaçáo desses parâmetros na mente de uma pessoa. (S4)

[...] varia assim, [...] de humor, não humor, mas comportamento mesmo, acho que crise psíquica pode ser ou se manifestar gritando, tendo uma crise mesmo ou também fica quieto, na dele, mais ou menos isso. (S6)

É evidenciado nesses discursos que a crise psíquica seria um conceito médico, sendo sua condição de caráter patológico, disfuncional e psiquiátrico. É perceptível que a maioria das expressóes utilizadas pelos trabalhadores dessa UPA tem semelhança, mesmo sendo eles profissionais que atuam em distintos setores, o que nos faz refletir que os parâmetros preconizados pela Reforma Psiquiátrica talvez não estejam sendo efetivos em suas noçôes e práticas. Mesmo que existam aparatos em saúde mental com uma visão muito além da formulação histórica da loucura, da biomedicina, da higienização, a crise psíquica ainda se localiza como uma denúncia a esse serviço, demonstrando a fragilidade, não apenas da UPA, mas da RAPS dessa região.

Apenas um dos profissionais da UPA trouxe um ponto de vista distinto dos demais.

Uma crise psíquica, [...] é um paciente que nos procura com uma condição, às vezes, menos clínica, do que uma condição que exige um tratamento diferenciado, às vezes clínico, às vezes não, por distúrbios que a prática nos mostra que eles são muito menos condicionados por um lema natural, que eles são muito menos causados por uma disfunção psíquica, psiquiátrica natural, um borderline, um distúrbio de bipolaridade, mas muito mais condicionadas, às vezes até a própria condição social. (G2) 
Esse trabalhador da gestão explora outras formas de abordagem para além da visão médica ou de um olhar atrelado à lógica da loucura, manifestando, em sua opinião, que tal crise teria uma influência de questóes sociais. Pode-se pensar, a partir disso, que existe um caráter de singularidade na crise psíquica, que está associado a múltiplos fatores do universo subjetivo de cada sujeito (BRITO; BONFADA; GUIMARÃES, 2015).

Apesar do comentário do trabalhador da gestáo, que trouxe um olhar diferenciado dos demais profissionais, exatamente por trazer uma dimensão mais subjetiva na forma de compreensão da crise psíquica, foi verificado, na maioria das falas, que a percepção dos trabalhadores da UPA sobre a crise psíquica é de cunho biomédico. Diante disso, podemos perceber que há uma hegemonia dos saberes médicos em relação ao conceituado como crise psíquica, mesmo que nela haja uma dimensão singular (JARDIM, 2008; 2014).

Ainda que a Reforma Psiquiátrica tenha gerado mudanças significativas para a saúde mental no Brasil, principalmente com a desinstitucionalização e com a criação de serviços substitutos aos modelos dos hospitais hegemônicos, ainda persiste a ideia da existência de uma espécie de manicômio. É verificado que a definição que teve mais destaque sobre a crise psíquica é baseada no modelo biológico, psiquiátrico e médico (PELBART, 1990).

Assim sendo, a partir dos conceitos apresentados pelos trabalhadores sobre crise psíquica, podemos compreender, de modo mais amplo, como é feito o acolhimento à pessoa em crise psíquica e se tais definiçôes podem interferir na postura que o profissional tem perante esse fenômeno. Com isso, será necessário compreender qual a visão dos trabalhadores dessa UPA sobre o acolhimento ao indivíduo que se encontra em uma emergência psicológica e/ou psiquiátrica, bem como perceber se existem fragilidades sobre a concepção de crise psíquica e o trabalho em saúde mental.

\section{O significado do acolhimento na UPA: percepção dos trabalhadores}

Neste segundo tópico, será analisada a visão que os trabalhadores da UPA apresentam sobre a dinâmica e sobre o processo de acolhimento à pessoa em crise psíquica dentro da unidade. Com isso, foram investigadas as relaçóes que os trabalhadores têm com aquilo que é pensando sobre saúde mental e acolhimento no âmbito da saúde. 
O acolhimento na saúde faz parte das relaçôes que o profissional estabelece com os usuários, pois é uma prática intrínseca no exercício do trabalho. Nesse viés, é algo que vai além de uma técnica/prática tradicional, centrada no modelo biomédico, ou seja, consiste numa intervenção com uma perspectiva humanitária, assistencial e biopsicossocial, uma postura que emprega o exercício da escuta qualificada, uma ferramenta ativa e que abrange, também, o protagonismo do usuário (BRASIL, 2004).

A diretriz do acolhimento interfere no posicionamento dos profissionais da saúde sobre os sujeitos que se encontram em estado de crise, já que a sua intenção é otimizada pela humanização e zela pelo uso de tecnologia leve. Segundo Merhy (2002), a sistemática de atendimento deve ser viva e dinâmica, cooperativa e corresponsável. $\mathrm{O}$ acolhimento não deve ser visto como um dispositivo fechado, e sim como um gesto dirigido a práticas voltadas ao outro, ou seja, é estar disponível, é orientar, é abraçar a causa, é dar o melhor de si para quem demanda, é buscar o espaço de saúde. Para compreendermos essa dinâmica do acolhimento dentro da UPA, um dos trabalhadores da gestão comenta:

Nós temos um protocolo de classificação de risco que é baseado no Manchester tem esse
primeiro atendimento ou acolhimento [...]. O sofrimento psicológico ele não é o mais
visado, e o mais importante segundo a visão de alguns profissionais, apesar dele ter uma
relevância muito grande, então, tem um certo preconceito no manejo e no atendimento
desse paciente muitas vezes, principalmente naqueles pacientes mais frequentes dentro da
unidade [...]. (G1)

Observa-se, nessa primeira fala, que o Gestor 1 demonstra que o acolhimento está baseado no Protocolo de Manchester, bem como que o atendimento de demandas mais subjetivas, no caso de crise psíquica, não seria prioridade para alguns profissionais do serviço. Tal fala, ainda, aborda o Acolhimento com Classificação de Risco, cujo intuito de utilização está em identificar que usuários precisam de atendimento imediato. Assim, centra-se em agilizar o processo e garantir a resolutividade baseada no grau de risco que o usuário apresenta (BRASIL, 2004). Desta forma, destaca-se que o acolhimento à pessoa em crise psíquica não é prioridade, pois os Protocolos de Classificação de Risco objetivam, geralmente, as questôes fisiológicas (VOLMER; BRIDI FILHO, 2016).

O Sistema Manchester de Classificação de Risco é um protocolo validado no âmbito internacional, oriundo da Inglaterra. Nesse protocolo, há quatro cores que definem a atenção do usuário, de acordo com a necessidade específica: vermelha 
(emergência clínica e traumática); amarela (pacientes críticos ou semicríticos); verde (pacientes não críticos); azul (consultas de baixa e média complexidade) (BRASIL, 2004; SILVA, et al., 2014). O Protocolo de Manchester está incluso na dinâmica de acolhimento da UPA e na classificação dos usuários que apresentam crise psíquica:

Paciente chega com quadro clínico psiquiátrico ele abre uma ficha pra ser avaliado na triagem a gravidade, o enfermeiro ele tria de forma subjetiva e de acordo com o que é relatado pra ele, ele vê o nível de gravidade daquele paciente, é claro que pacientes com crises, crises de exaustão e agressividade normalmente já são alocados pra laranja, amarelo, pacientes com ideaçáo suicida [...] o quadro psíquico sempre vai ser moderado a grave. (S4)

Nota-se que o usuário que chega na UPA em estado de crise psíquica recebe classificação segundo o Protocolo de Manchester: urgente, cor amarela (pacientes críticos ou semicríticos) ou cor laranja; intermediário, entre a amarela e a vermelha, ou seja, pacientes mais graves; emergentes, mas não tanto, quanto da cor vermelha, mas também com um alto risco. Verifica-se, nessa fala, que, já no processo de triagem, a crise psíquica tem um destaque como emergência psiquiátrica a partir dos protocolos; todavia, ela não é o suficiente para situar que a crise psíquica é uma circunstância de fragilidade e que necessita de atençáo imediata.

$\mathrm{Na}$ sequência, encontram-se as falas de um trabalhador de apoio (A2) e de duas trabalhadoras da saúde (S1 e S3):

A gente contém o paciente, ele é contido e já medicado pra se acalmar pra ele não ficar agitado pra não estar se machucando ou machucar um colega, é assim que funciona. A2

Bom, elas passam pela triagem, pela classificação de risco, direto pro médico, eles têm a preferência, vai direto para o médico para ter a assistência muitas vezes eles são medicados [...]. A contenção se eles estáo agitados e tendo risco de se autoagredir e agredir aos outros, daí sim, eles necessitam de uma contenção [...]. (S1)

As vezes a gente precisa usar a força física, precisamos conter em maca, usando de compressas, de ferramentas para deixa ele imóvel, antes de usar a medicaçóes, depois, aí sim, a gente faz o uso de drogas para poder sedar ou deixar a pessoa mais calma. Normalmente a gente tem ou opta por isso até pela nossa segurança, pela segurança dos outros. (S3)

Diante disso, podemos acompanhar a forma com que os trabalhadores empregam a dinâmica do acolhimento em casos de agressividade e ideação suicida, enfatizando que esses casos são logo avaliados como emergência. Evidencia-se, nesses comentários, que os trabalhadores da UPA, em casos muito graves (com riscos de agressão física), encontram, na contenção e na medicação, modos de lidar com tais fenômenos. Assim sendo, compreende-se que existem desafios para lidar 
com um usuário que expóe uma agressividade com riscos, tanto para si como para outras pessoas, e a alternativa seria a contenção e a medicação como meios mais rápidos para apaziguar a crise.

De acordo com a Portaria no 2.048, de 5 de novembro de 2002, o acolhimento às urgências, nas unidades de urgência e de emergência, inclui quadros de pacientes agitados, violentos, depressivos com risco de suicídio, além dos dependentes de substâncias psicoativas. Nesse contexto, a ação é acolher e reconhecer os sinais apresentados e acionar métodos para lidar com as circunstâncias quando houver risco para o paciente e/ou para a equipe.

Com isso, já podem ser visualizadas algumas dificuldades que os trabalhadores da UPA encontram ao lidar com uma pessoa em um estado de extrema agressividade, demonstrando que os protocolos apresentam uma insuficiência quando são utilizados como algo central no acolhimento e não como um auxílio (JARDIM, 2014). Esses sujeitos com grau mais acentuado de crise psíquica transparecem as fragilidades da UPA e do sistema que o detém, elucidando que algo precisa ser modificado.

Observa-se também certa angústia nas falas dos profissionais, não porque a intenção é não machucar o usuário que se encontra em estado altamente agressivo, mas porque não encontram outras formas para acolher tais pacientes. Esse trabalhador da saúde comenta sobre o acolhimento à pessoa em crise psíquica:

Como que a gente acolhe aqui ou como é, como eu ia dizendo, tenta fazer uma conversa não invasiva, mais neutra possível que a gente não pode acabar interferindo no que ela quer te dizer ou naquilo que ela não quer te dizer. Nós, da enfermagem, a gente não recebe um treinamento específico pra isso [...] talvez não seja o melhor porque a gente não tenha o conhecimento técnico pra isso. (S2)

O comentário desse trabalhador demonstra que os métodos utilizados para acolher uma pessoa em crise psíquica talvez não sejam os melhores, pois a equipe não tem uma preparação específica para atendimentos dessas demandas. Esse profissional do apoio também demonstra uma semelhança em relação à fala do Trabalhador da Saúde S2:

Olha, acredito que poderia melhorar, mas pro que a gente tem disponível, acho que felizmente é dependendo de cada caso, então, as vezes, ali tem um pessoal mais agressivo e o pessoal tenta conversa, tenta acalma, senão é o mais adequado que pelo menos [...] é isso, o pessoal chama pra conversa, as vezes ficam meio, é [...] se não dá o diálogo tem que fazer algum procedimento a mais ali, alguma medicaçâo, alguma coisa pra tentar acalmar aquela pessoa, aquela agressividade ou a pessoa que tá em desespero ali [...]. (A1) 
Perante as dificuldades encontradas na pesquisa e mencionada pelos próprios profissionais, para trabalhar suas compreensóes e seus fazeres, seria interessante haver espaços de educação permanente que abordassem tal temática. Essa é uma demanda que ganha relevância e que necessita de uma abordagem resolutiva, ou seja, de uma escuta mais ampla, voltada à vinculação e ao encaminhamento do sujeito, a fim de melhor acompanhamento do caso. Todavia, se não houver um espaço destinado à reflexão, à educaçáo permanente, pode-se continuar a repetir o ciclo, sem atender as necessidades da saúde do usuário, insistindo na oferta de serviços que dificultam a reflexão sobre suas práticas e sobre, em específico, as demandas da saúde mental (BRASIL, 2014).

Verifica-se, nessas expressões, que o manejo de pessoas em crise psíquica aguça angústia e tensão nos profissionais. Nesse sentido, há certa dificuldade, por parte dos trabalhadores, quanto a formas de acolhimento, mesmo com todo o processo de desinstitucionalizaçáo e com a criação de serviços substitutos aos modelos manicomiais, preconizado pela Reforma Psiquiátrica. Os métodos utilizados diante da pessoa em crise psíquica ainda estão centrados no saber biomédico (JARDIM, 2008; 2014). Apesar dos obstáculos que o manejo do usuário com crise psíquica manifesta, a educação permanente poderia a ser uma das alternativas para lidar com essas necessidades entre os trabalhadores dentro da UPA. Entretanto, a educação permanente náo engloba a complexidade que a crise psíquica aborda no contexto de saúde mental, mas é uma alternativa para se pensar, colocando-a dentro da realidade da UPA, cujo objetivo é a estabilização e o encaminhamento dos casos de crise psíquica (ANDRADE; ZEFERINO; FIALHO, 2016).

Ademais, é perceptível a importância das conexôes que a RUE precisa ter com a RAPS municipal, pois a fragmentação na relação dos serviços de saúde dificulta o acolhimento desses usuários. O isolamento dos órgãos de saúde, conforme se observa, não auxilia nos processos de reabilitação psicossocial; apesar disso, dentro da RAPS, são preconizados apoio matricial, responsabilização e corresponsabilização, atuação com a clínica ampliada, intersetoriedade, entre outras práticas vitais em saúde mental, uma vez que interferem no acolhimento à pessoa com crise psíquica (MEDEIROS, et al, 2016).

\section{Considerações finais}

Pode-se analisar, a partir das entrevistas, que o conceito de crise psíquica está atrelado ao estado que uma pessoa se encontra para além de sua conduta "normal". 
Muitos trabalhadores da saúde enfatizaram um estado de desequilíbrio que os usuários manifestam, cada um de modo distinto - alguns são mais contidos, outros mais agressivos, e, por causas diversas, depressão, transtornos de personalidade (como esquizofrenia) e dependência de álcool ou outras substâncias psicoativas.

É interessante visualizar que o conceito de crise psíquica apresentado pelos trabalhadores da UPA interfere na conduta e no posicionamento que eles manifestam quando atendem uma pessoa na situação referida, ou seja, no modo como eles irão proceder no acolhimento. Alguns trabalhadores comentaram sobre os usuários em condições psicológicas graves, quando não viam alternativas senão a contenção e o medicamento como um meio de trazer o sujeito à normalidade.

Ainda há um caráter manicomial no modo de pensar dos trabalhadores, até pela falta de espaço para refletir sobre suas práticas. Tal consideração é válida, já que nunca se teve capacitação sobre como lidar com uma pessoa em crise psíquica, sendo que essa UPA é a referência na cidade em casos de surtos psiquiátricos. Isso demonstra que, mesmo com a alta demanda de saúde mental no serviço, ainda não é dada a ela a devida atenção.

Em consequência, os cuidados para com uma pessoa em um contexto de crise exigem certas mutaçóes, principalmente na disposição da equipe para o acolhimento e a escuta do sujeito, buscando proporcionar um ambiente confortável para estruturação de um possível vínculo. Todavia, há obstáculos perceptíveis dos profissionais de saúde em englobar novas tecnologias na assistência à crise em saúde mental, em virtude de ser algo de caráter mais subjetivo (FIALHO, 2015; PEREIRA, 2015).

Portanto, o sujeito em crise psíquica enuncia que questóes precisam ser refletidas, seja sobre sistema de saúde, seja sobre as práticas que estão sendo constituídas e/ ou estão em construção em relação ao se acolhimento, porquanto se encontra em extremo sofrimento psíquico. Tais indagaçóes, no entanto, não devem ser direcionadas à UPA, tampouco nela centralizadas; devem se estender à Rede de Atenção Psicossocial e ao campo social. Esse sujeito está demonstrando que não existe um método para amparar uma pessoa em crise, que o acolhimento é algo que se constrói no vínculo, na relação, e que não será um protocolo que dará conta disso, mas a relação construída entre gestores/profissionais/usuários, vivenciada em ato e experienciada para além dos parâmetros médicos. ${ }^{2}$ 


\section{Referências}

ALMEIDA, A. B. et al. Atendimento Móvel de Urgência na Crise Psíquica e o Paradigma Psicossocial. Texto Contexto Enfermagem Florianópolis, v. 24, n. 4, p. 1035-1043, out-dez. 2015. Disponível em: <http://www.scielo.br/pdf/tce/v24n4/pt_0104-0707-tce-24-04-01035.pdf> Acesso em: 20 abr. 2019.

. Intervenção nas situaçóes de crise psíquica: dificuldades e sugestóes de uma equipe de atenção pré-hospitalar. Revista Brasileira de Enfermagem, v. 67, n. 5, p. 708-714, set-out. 2014. Disponível em: <http://www.scielo.br/pdf/reben/v67n5/0034-7167-reben-67-05-0708. pdf $>$ Acesso em: 20 abr. 2019.

ANDRADE, K.; ZEFERINO, M. T.; FIALHO, M. B. Articulação da Rede de Atenção Psicossocial para o Cuidado às Crises. Psicologia em Estudo, v. 21, n. 2, 2016. Disponível em: <https://www. redalyc.org/jatsRepo/2871/287147424005/html/index.html> Acesso em: 14 abr. 2020.

AMARANTE, P.; NUNES, M. de O. A reforma psiquiátrica no SUS e a luta por uma sociedade sem manicômios. Ciência \& Saúde Coletiva, v. 23, n. 6, p. 2067-2074, 2018. Disponível em: <http://www.scielo.br/scielo.php?pid=S1413-81232018000602067\&script=sci_ abstract\&tlng=pt> Acesso em: 20 abr. 2019.

AMORIN, A. K. de M. A.; DIMENSTEIN, M. Desinstitucionalização em saúde mental e práticas de cuidado no contexto do serviço residencial terapêutico. Ciência \& Saúde Coletiva, v. 14, n. 1, p. 195-204, 2009. Disponível em: <http://www.scielo.br/scielo.php?script=sci_arttext \&pid=S1413-81232009000100025> Acesso em: 20 abr. 2019.

BARDIN, L. Análise de conteúdo. Lisboa: Edições 70, 1977.

BRASIL. Conselho Nacional de Secretários de Saúde. Legislação do SUS. Brasília: CONASS, 2003. Disponível em: <http://bvsms.saude.gov.br/bvs/publicacoes/progestores/leg_sus.pdf> Acesso em: 27 abr. 2019.

. Ministério da Saúde. Acolhimento nas Práticas de Produção de Saúde. Brasília: MS,

2010. Disponível em: <http://bvsms.saude.gov.br/bvs/publicacoes/acolhimento_praticas_ producao_saude.pdf> Acesso em 20 abr. 2019.

. Ministério da Saúde. Educação Permanente em Saúde. Brasília: MS, 2014. Disponível em: <http://bvsms.saude.gov.br/bvs/folder/educacao_permanente_saude.pdf> Acesso em: 15 dez. 2019.

Ministério da Saúde. HumanizaSUS: Acolhimento com Avaliação e Classificação de Risco: Um Paradigma Ético-Estético no Fazer em Saúde. Brasília, MS, 2004. Disponível em: <http://bvsms.saude.gov.br/bvs/publicacoes/acolhimento.pdf> Acesso em: 27 abr. 2019.

. Ministério da Saúde. HumanizaSUS: Política Nacional de Humanização - PNH. Brasília, 2013. Disponível em: <http://bvsms.saude.gov.br/bvs/publicacoes/politica_nacional_ humanizacao_pnh_folheto.pdf> Acesso em: 27 abr. 2019. 
. Ministério da Saúde. Portaria no 1.020, de 13 de maio de 2009. Estabelece diretrizes para a implantação do componente pré-hospitalar fixo para a organização de redes locorregionais de atenção integral às urgências em conformidade com a Política Nacional de Atenção às Urgências. Diário oficial da União, Brasília, 15 maio 2009. Disponível em: <http://bvsms.saude. gov.br/bvs/saudelegis/gm/2009/prt1020_13_05_2009.html> Acesso em: 27 abr. 2019.

. Ministério da Saúde. Portaria no 10, de 3 de janeiro de 2017. Redefine as diretrizes de modelo assistencial e financiamento de UPA $24 \mathrm{~h}$ de Pronto Atendimento como Componente da Rede de Atenção às Urgências, no âmbito do Sistema Único de Saúde. Brasília, 2017. Disponível em: <http://bvsms.saude.gov.br/bvs/saudelegis/gm/2017/prt0010_03_01_2017.html> Acesso em: 20 abr. 2019.

. Ministério da Saúde. Portaria no 2048, de 5 de novembro de 2002. O Ministro de Estado da Saúde, no uso de suas atribuiçóes legais, considerando que a área de Urgência e Emergência constitui-se em um importante componente da assistência à saúde. Brasília, nov. 2002. Disponível em: <http://bvsms.saude.gov.br/bvs/saudelegis/gm/2002/prt2048_05_11_2002. html> Acesso em: 20 abr. 2019.

. Ministério da Saúde. Saúde Mental e Atenção Básica: o vínculo e o diálogo necessários. Inclusão das ações de Saúde Mental na Atenção Básica. Circular Conjunta, no 01/03, Brasília, 2007. Disponível em: <https://www.nescon.medicina.ufmg.br/biblioteca/imagem/1734.pdf> Acesso em: 13 maio 2019.

. Ministério da Saúde. Secretaria de Atenção à Saúde. Política Nacional de Humanização da Atenção e Gestão do SUS. Acolhimento e classificação de risco nos serviços de urgência. Brasília, 2009. Disponível em: <http://bvsms.saude.gov.br/bvs/publicacoes/acolhimento_classificaao_ risco_servico_urgencia.pdf> Acesso em: 27 abr. 2019.

BRITO, A. A. C.; BONFADA, D.; GUIMARÃES, J. Onde a reforma ainda não chegou: ecos da assistência às urgências psiquiátricas. Physis Revista de Saúde Coletiva. Rio de Janeiro, v. 25, n. 4, p. 1293-1312, 2015. Disponível em: <http://www.scielo.br/scielo.php?pid=S010373312015 000401293\&script=sci_abstract\&tlng=pt $>$ Acesso em: 13 maio 2019.

CANGUILHEM, G. O normal e o patológico. Rio de Janeiro: Forense Universitária, 1978.

COELHO, M. T. Á. D. Concepçôes de normalidade e saúde mental entre infratores presos de uma unidade prisional da cidade do Salvador. Ciência \& Saúde Coletiva, v. 14, n. 2, p. 567-575, 2009. Disponível em: <http://www.scielo.br/scielo.php?script=sci_arttext\&pid $=$ =S1413-81232009000200025> Acesso em: 13 maio 2019 .

DELL'ACQUA, G.; MEZZINA, R. Resposta à crise: estratégia e intencionalidade da intervenção no serviço psiquiátrico territorial. In: AMARANTE, P. D. C. (Org.). Archivos de saúde mental e atenção psicossocial. Rio de Janeiro: Nau, v.2, 2005. p. 161-94. 
DIMENSTEIN, M. et al. O atendimento da crise nos diversos componentes da rede de atenção psicossocial em Natal-RN. Revista Polis e Psique, v. 2, n. 3, p. 95-127, 2012. Disponível em: <https://seer.ufrgs.br/PolisePsique/article/view/40323> Acesso em: 25 maio 2019.

FERREIRA, G. M. Acolhimento: um processo em construção. Belo Horizonte: Corinto, 2009. Disponível em: <https://www.nescon.medicina.ufmg.br/biblioteca/imagem/2258.pdf> Acesso em: 13 maio 2019 .

FIALHO, M. B. Contextos históricos e concepções teóricas da crise e urgência em saúde mental. In: ZEFERINO, M. T.; RODRIGUES, J.; ASSIS, J. T. (Orgs.). Crise e Urgência em Saúde Mental: fundamentos da atenção à crise e urgência em saúde mental. Florianópolis: UFSC, 2015. Disponível em: <file://C:/Users/bibia/Downloads/Modulo2-Crise-2015-2_final\%20(4). pdf> Acesso em: 13 maio 2019.

FONSECA, T. M. G.; JAEGER, R. L. A psiquiatrização da vida: arranjos da loucura hoje. In: BRASIL. Ministério da Saúde. Cadernos Humaniza SUS - Saúde Mental, v. 5, Brasília, 2015. Disponível em: <http://bvsms.saude.gov.br/bvs/publicacoes/saude_mental_volume_5.pdf> Acesso em: 20 abr. 2019.

FOUCAULT, M. A história da loucura na idade clássica. São Paulo: Perspectiva, 2010.

. Ditos e escritos I: Problematização do sujeito: psicologia, psiquiatria e psicanálise. Rio de Janeiro: Forense Universitária, 2006. . Microfísica do Poder. Rio de Janeiro: Graal, 2007.

FRAYSE-PEREIRA, J. O que é loucura. São Paulo: Brasiliense, 2008.

JARDIM, K. F. de S. B. Habitando Paradoxo: Atenção à Pessoa em Crise no Campo da Saúde Mental. Tese (Doutorado) - Escola Nacional de Saúde Pública Sergio Arouca, Rio de Janeiro, 2014. Disponível em: <https://www.arca.fiocruz.br/handle/icict/13139> Acesso em: 27 abr. 2019.

. OServiço Ambulatorial Móvel de Urgência (SAMU) no Contexto da Reforma Psiquiátrica:

Em Análise a Experiência de Aracaju/SE. Dissertação (Mestrado em Psicologia) - Universidade Federal do Rio Grande do Norte, Centro de Ciências Humanas, Letras e Artes, Programa de Pós-Graduação em Psicologia, Natal, Rio Grande do Norte, 2008. Disponível em: <https:// repositorio.ufrn.br/jspui/handle/123456789/17411> Acesso em: 20 abr. 2019.

MEDEIROS, P. F. P. et al. Rede de Atenção Psicossocial no Sistema Único De Saúde (SUS) - Eixo Políticas e Fundamentos. Aberta: Portal de Formação a Distância, Sujeito, Contextos e Drogas. 2016. Disponível em <http://www.aberta.senad.gov.br/medias/ original/201704/20170424-094953-001.pdf> Acesso em: 14 abr. 2020.

MERHY, E. E. Saúde: a cartografia do trabalho vivo. São Paulo: Hucitec, 2002. 
MINÓIA, N. P.; MINOZZO, F. Acolhimento em Saúde Mental: operando mudanças na Atenção Primária à Saúde. Psicologia: Ciência e Profissão, v. 35, n, 4, p. 1340-1349, 2015. Disponível em: <http://www.scielo.br/scielo.php?pid=S141498932015000401340\&script=s ci_abstract\&tlng=pt $>$ Acesso em: 13 maio 2019.

OLIVEIRA, D. A.; GUIMARÁES, J. P. A importância do acolhimento com classificação de risco nos serviços de emergência. Caderno Saúde e Desenvolvimento, v. 2, n. 2, jan-jun. 2013. Disponível em: <https:/www.uninter.com/revistasaude/index.php/cadernosaudedesenvolvimento/article/ view/197> Acesso em: 13 maio 2019.

PAIVA, C. H. A.; TEIXEIRA, L. A. Reforma sanitária e a criação do Sistema Único de Saúde: notas sobre contextos e autores. História, Ciências, Saúde Manguinhos, Rio de Janeiro, v. 21, n. 1, p. 15-35, jan-mar. 2014. Disponível em: <http://www.scielo.br/pdf/hcsm/v21n1/0104-5970hcsm-21-1-00015.pdf> Acesso em: 13 maio 2019.

PAULON, S. M. et al. O foco míope: apontamentos sobre o cuidado à crise em saúde mental em emergências de hospitais gerais. Polis e Psique, v. 2, n. 3, p. 73-94, 2012. Disponível em: <https://seer.ufrgs.br/PolisePsique/article/view/40322> Acesso em: 25 maio 2019.

PELBART, P. P. Manicômio Mental: a outra face da clausura. In: LANCETTI, A. Saúde Loucura. São Paulo: Hucitec, 1990.

PEREIRA, P. A. Pronto Atendimento Suplementar: beneficiário em situação de crise em saúde mental. Dissertação (Mestrado), Universidade Federal de Santa Catarina, Florianópolis, 2015. Disponível: <https://repositorio.ufsc.br/handle/123456789/160774> Acesso em: 13 maio 2019. SILVA, M. de F. N. et al. Protocolo de avaliação e classificação de risco de pacientes em unidade de emergência. Revista Latino-Americana de Enfermagem, v. 2, n. 22, p. 218-225, mar-abr. 2014. Disponível em: <http://www.scielo.br/scielo.php?pid=S0104-11692014000200218\&script=sci_ arttext\&tlng=pt $>$ Acesso em: 27 abr. 2019.

SILVA, G. S. et al. Redes de atenção às urgências e emergências: pré-avaliação das Unidades de Pronto Atendimento (UPAs) em uma região metropolitana do Brasil. Revista Brasileira de Saúde Materno-Infantil, Recife, v. 12, n. 4, p. 445-458, out-dez. 2012. Disponível em: <http://www.scielo. br/scielo.php?script=sci_arttext\&pid=S1519-38292012000400011> Acesso em: 13 maio 2019.

SILVEIRA, L. C.; BRAGA, V. A. B. Acerca do conceito de loucura e seus reflexos na assistência de saúde mental. Revista Latino-Americana de Enfermagem, v. 13, n. 4, p. 591595, jul-ago. 2005. Disponível em: <http://www.scielo.br/scielo.php?script=sci_arttext\&pid =S0104-11692005000400019> Acesso em: 20 abr. 2019.

SOUZA, A. dos S. et al. Estratégias de atendimento à crise psíquica por um serviço de atendimento móvel de urgência. Journal of Nursing and Health, n. 1, v. 9, 2019. Disponível em: <https://periodicos.ufpel.edu.br/ojs2/index.php/enfermagem/article/view/15019> Acesso em: 25 maio 2019. 
UCHIMURA, L. Y. T. et al. Unidades de Pronto Atendimento (UPAs): características da gestão às redes de atenção no Paraná. Saúde Debate, Rio de Janeiro, v. 39, n. 107, p. 972-983, out-dez. 2015. Disponível em: <http://www.scielo.br/pdf/sdeb/v39n107/0103-1104-sdeb-39-107-00972. pdf $>$ Acesso em: 13 maio 2019.

VOLMER, A. L.; BRIDI FILHO, C. A. N. Protocolo de Manchester em pauta: como este aborda as questôes de saúde mental? Disciplinarum Scientia. Santa Maria, v. 17, n. 1, p. 103-116, 2016. Disponível em: <file://C:/Users/bibia/Downloads/2022-5672-2-PB.pdf> Acesso em: 25 maio 2019.

\section{Notas}

${ }^{1}$ Os termos aqui empregados, a exemplo de "usuário", encontram-se, por convenção, no masculino; porém, precisam ser compreendidos como referência a sujeitos ou a indivíduos como um todo, indistintamente.

${ }^{2}$ B. M. Homercher e A. L. Volmer: elaboração da pesquisa, coleta de dados, transcrição e análise dos dados e revisão bibliográfica. 


\section{Abstract}

\section{Interlocution between reception and psychic crisis: perception of an Emergency Care Unit workers}

The Brazilian Psychiatric Reform Law provides for the care and attention to the person in a mental crisis and based on this document, such demands became a key point for health services, including emergency units and of emergency. Based on this normative, we aimed to analyze the notions that professionals have regarding reception and the psychic crisis. We used exploratory qualitative research, which conducted semi-structured interviews with 11 professionals from different sectors of an Emergency Care Unit (ECU) in the interior of Rio Grande do Sul state, Brazil. Content analysis was used, in which two emerging categories were found: 1) Notion of psychic crisis for ECU professionals and 2) Notions and practices of reception to the psychic crisis exercised by ECU workers. The results show that both the notion of psychic crisis and the welcoming practices employed by workers, in general, are associated with the biomedical model, with difficulty to broaden the understanding and ways of welcoming individuals in crisis. In this sense, the notion of ECU workers under study, in relation to the reception of the person in a mental crisis, is not articulated with what the Psychiatric Reform Law advocates.

Keywords: reception; psychic crisis; Emergency Care Unit. 